\title{
Femoral revision knee Arthroplasty with Metaphyseal sleeves: the use of a stem is not mandatory of a structural point of view
}

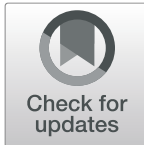

\author{
F. Fonseca', A. Sousa ${ }^{2}$ and A. Completo ${ }^{2 *}$
}

\begin{abstract}
Purpose: Although metaphyseal sleeves are usually used with stems, little is known about the exact contribution/ need of the stem for the initial sleeve-bone interface stability, particularly in the femur, if the intramedullary canal is deformed or bowed. The aim of the present study is (1) to determine the contribution of the diaphyseal-stem on sleeve-femur interface stability and (2) to determine experimentally the strain shielding effect on the metaphyseal femur with and without diaphyseal-stem. It is hypothesised that diaphyseal-stem addition increases the sleevefemur interface stability and the strain-shielding effect on the metaphyseal femur relatively to the stemless condition.

Material and methods: The study was developed through a combined experimental and finite-element analysis approach. Five synthetic femurs were used to measure cortex strain (triaxial-rosette-gages) behaviour and implant cortex micromotions (Digital Image Correlation) for three techniques: only femoral-component, stemless-sleeve and stemmed-sleeve. Paired t-tests were performed to evaluate the statistical significance of the difference of cortex strains and micromotions. Finite-element models were developed to assess the cancellous bone strain behaviour and sleeve-bone interface micromotions; these models were validated against the measurements.
\end{abstract}

Results: Cortex strains are significantly reduced $(p<0.05)$ on the stemmed-sleeve with a $150 \mu$ strain mean reduction at the medial and lateral distal sides which compares with a $60 \mu$ strain mean reduction $(p>0.05)$ on the stemless condition. Both techniques presented a mean cancellous bone strain reduction of $700 \mu$ strain (50\%) at the distal region and a mean increase of $2500 \mu$ strain (4x) at the sleeve proximal region relative to the model only with the femoral component. Both techniques presented sleeve-bone micromotions amplitude below 50-150 $\mu \mathrm{m}$, suitable for bone ingrowth.

Conclusions: The use of a supplemental diaphyseal-stem potentiates the risk of cortex bone resorption as compared to the stemless-sleeve condition; however, the stem is not essential for the enhancement of the initial sleeve-bone stability and has minor effect on the cancellous bone strain behaviour. Based on a purely structural point view, it appears that the use of a diaphyseal-femoral-stem with the metaphyseal sleeve is not mandatory in the revision TKA, which is particularly relevant in cases where the use of stems is impracticable.

Keywords: Experimental strains, Finite element model, Metaphyseal sleeve, Stress-shielding, Total knee arthroplasty, Revision, Metaphyseal bony defects

\footnotetext{
* Correspondence: completo@ua.pt

${ }^{2}$ Mechanical Engineering Department, University of Aveiro, 3810-193 Aveiro, Portugal

Full list of author information is available at the end of the article
}

\section{Springer Open}

(c) The Author(s). 2020 Open Access This article is licensed under a Creative Commons Attribution 4.0 International License, which permits use, sharing, adaptation, distribution and reproduction in any medium or format, as long as you give appropriate credit to the original author(s) and the source, provide a link to the Creative Commons licence, and indicate if changes were made. The images or other third party material in this article are included in the article's Creative Commons licence, unless indicated otherwise in a credit line to the material. If material is not included in the article's Creative Commons licence and your intended use is not permitted by statutory regulation or exceeds the permitted use, you will need to obtain permission directly from the copyright holder. To view a copy of this licence, visit http://creativecommons.org/licenses/by/4.0/. 


\section{Introduction}

In revision TKA (Total Knee Arthroplasty), the integrity of the remaining bone stock, once the primary components have been removed, often presents a challenge to obtain durable long-term fixation of the revision components. In these scenarios, the metaphyseal region of the bone has been recognized by its importance to the overall stability of a revision construct $[15,25]$. The reconstructive techniques, including bone allograft, morselized allograft, prosthetic composites, and custom prostheses have been used, with conflicting clinical results $[18,21,27]$. With these techniques, the metaphyseal region has been underutilized, as stability is typically achieved in the epiphysis and diaphysis. Recently, metaphyseal sleeves have gained popularity as an option for patients with severe metaphyseal bony defects requiring revision TKA $[9,17]$. Metaphyseal sleeves function as prosthetic structural grafts, as they allow the transfer of load from the revision components to the metaphyseal region. The potential for bony biologic fixation is a substantial benefit, when considering the use of metaphyseal sleeves. Initial sleeve stability is often achieved with use of diaphyseal-stems $[1-3,12,20,22,31,32]$, though few clinicians had used sleeves without stems [13, 28]. Currently, there is no consensus whether to use diaphyseal stems with metaphyseal sleeves or not [17]. Short and mid-term results have been promising; however, there are no long-term studies concerning durability [33]. The clinical results remain encouraging, but little is known about the exact structural contribution of the diaphyseal-stem for the initial sleeve-bone stability, particularly in cases where the use of stems is impracticable as bowed femoral intramedullary canals. Moreover, the stemless condition contributes to simplify the bone preparation thereby reducing operating time and reduces the revision cost. Construct stability is an important factor for the extent of biologic incorporation in the sleeve, thus enhancing the longevity of the revision procedure; however, the use of massive metal components as the sleeve and the stem changes the strain-stress bone behaviour. The purpose of the present study is (1) to determine the contribution of the diaphyseal-stem on sleevefemur interface stability and (2) to determine experimentally the strain-shielding effect on the metaphyseal femur with and without diaphyseal-stem. It is hypothesised that diaphyseal-stem addition increases the sleeve-femur interface stability and the strain-shielding effect on the metaphyseal femur relatively to the stemless condition.

\section{Methods}

\section{Experimental model}

The study was developed through a combined experimental and finite-element modelling approach. Experimental models were developed to measure cortical strains and femoral-component/cortical-bone micromovements. Finite-element models were developed to evaluate cancellous bone strains and sleeve-cancellous bone micromovements and they were validated against measured strains and micromovements. In what concerns the experiments, five synthetic femurs (4th generation, left, mod. 3406, from Pacific Research Labs, Vashon Island, WA, USA) were selected. The physical structure of this type of synthetic bone presented stiffness and strains close to the ones measured with natural bones, exhibiting extremely low specimen-to-specimen variability [16]. The metaphyseal bone defect analysed in the present study simulates a clinical scenario of a contained-bone-defect with a volume identical to the applied metaphyseal sleeve. Each femur was tested with three different construct techniques: first only with the femoral component (A), then with the sleeve (B) and finally with the sleeve fastened with the diaphyseal stem (C) (Fig. 1). After each test, the construct and cement were carefully removed to avoid femur damage to perform subsequent construct configuration. The preparation of femoral diaphysis begins with intramedullary femoral alignment, reaming of the medullary canal until a firm endosteal engagement is reached, sequential broaching of the metaphysis to the sleeve size, femoral distal cuts, notch resection and finally femoral trial assembly. Left femoral-component TC3 (size 4), metaphyseal sleeve (size 31) and the diaphyseal-fluted-stem (size $75 \mathrm{~mm} \times 16 \mathrm{~mm}$ ) of the P.F.C Sigma Knee System (DePuy-International, Johnson\&Johnson-Warsaw, USA) were all connected through the femoral adapter bolt (neutral position) and the femoral adapter-to-femoral component (7 degrees valgus angle) (Fig. 1). Only the

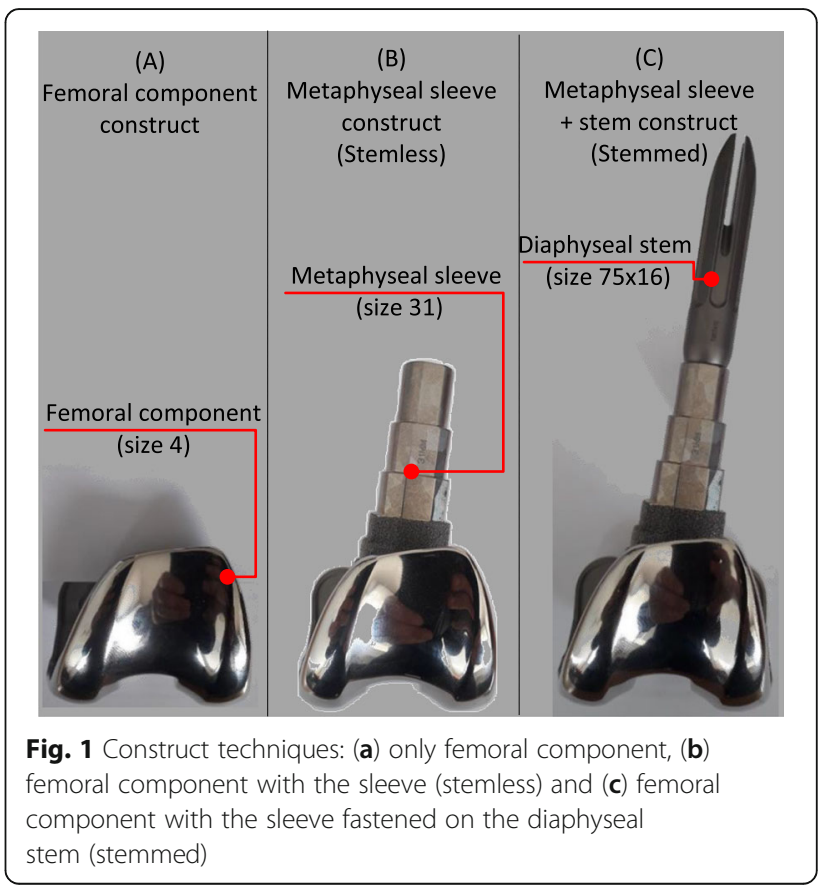


femoral component was cemented (CMW-1) at the distal cut surfaces with a mean thickness of $2 \mathrm{~mm}$ (Fig. 2), which is the most common practice in revision with metaphyseal-sleeves.

\section{Testing protocol}

Six triaxial strain gauges (KFG-3-120-D17-11L3M2S Kyowa-Electronic-Instruments, Japan) were glued to the distal femur at the medial (Md, Mp), lateral ( $\mathrm{Ld}, \mathrm{Lp})$,
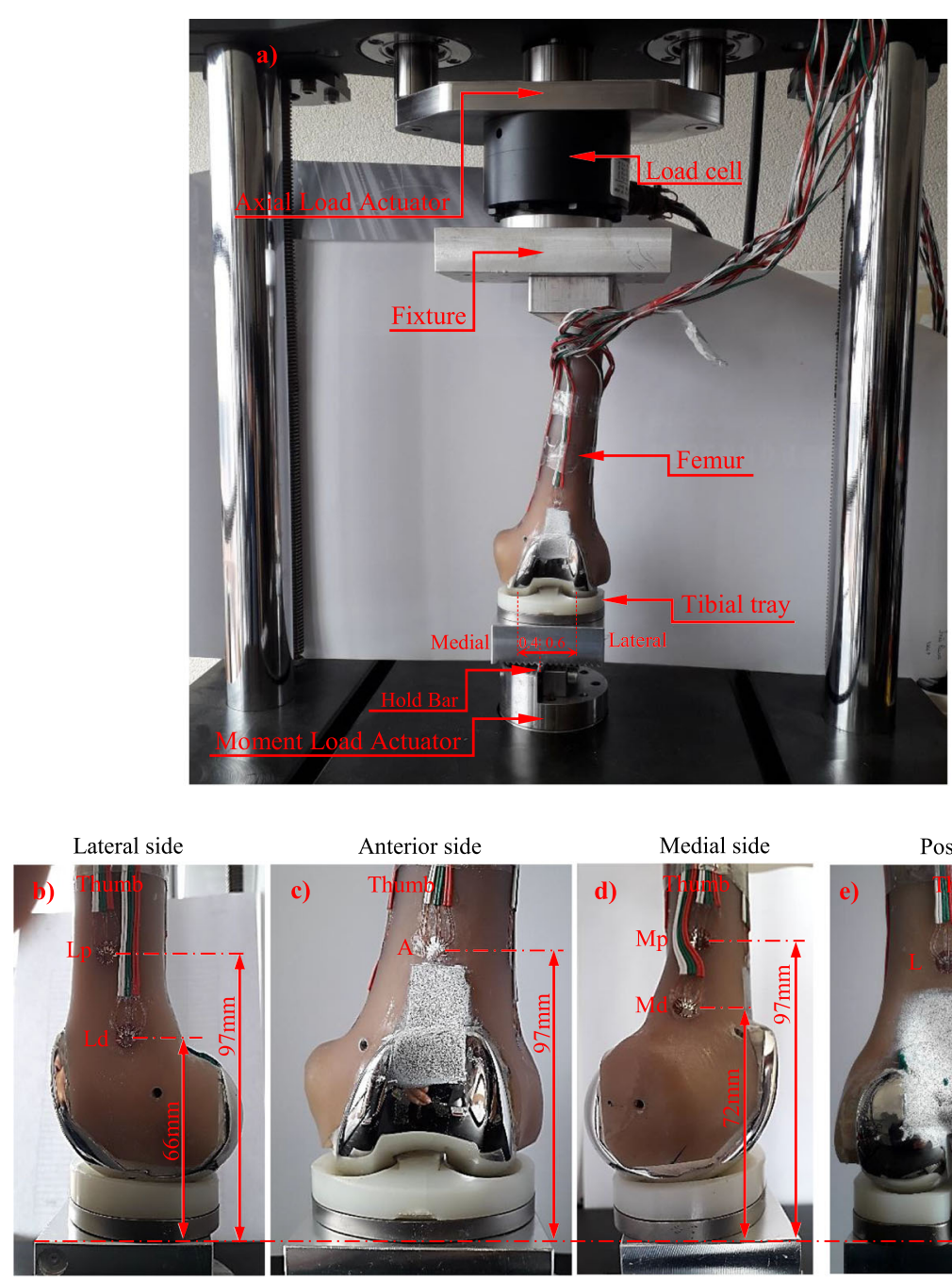

Medial side
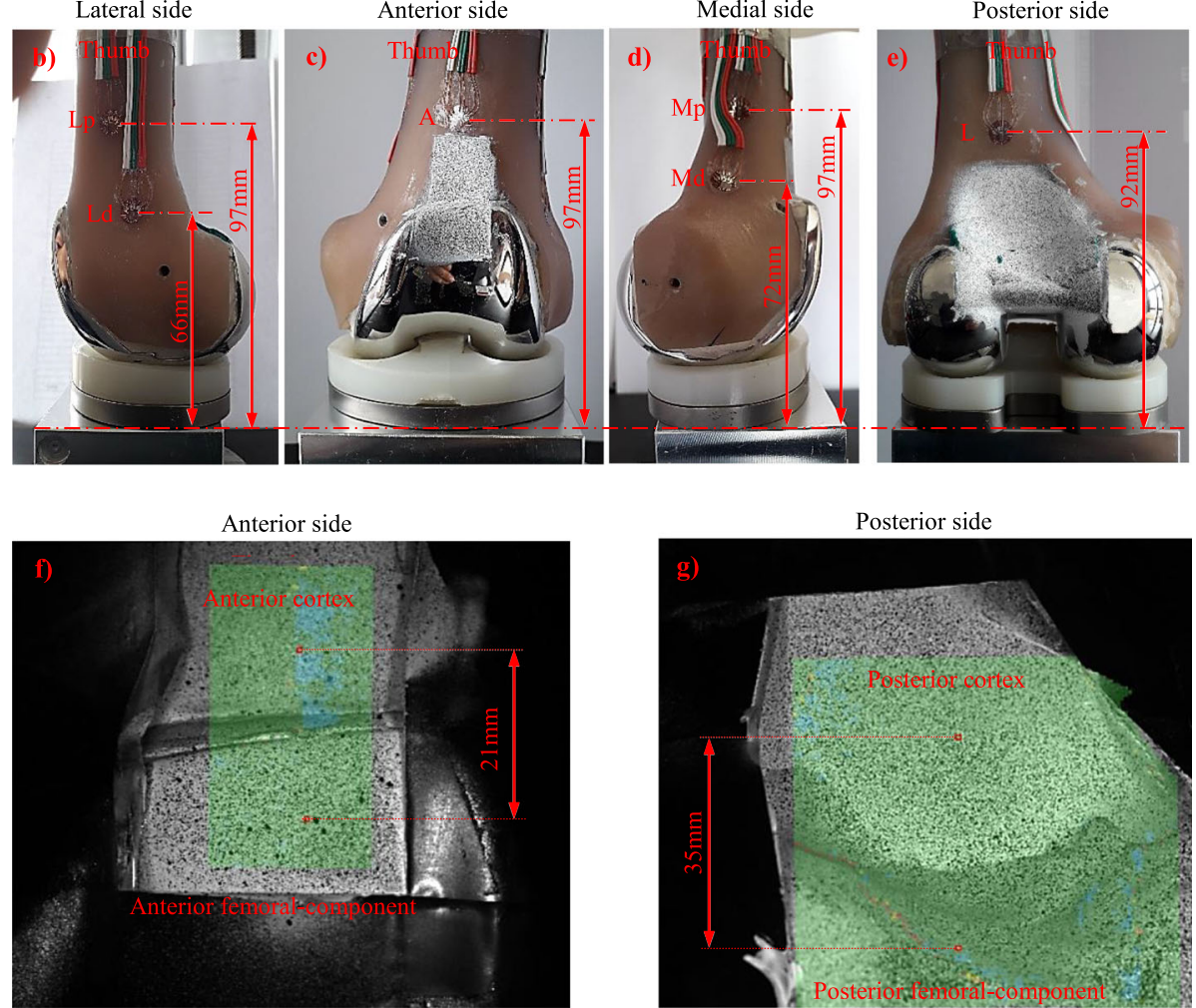

Fig. 2 a Loading machine and experimental setup; b Strain gauges locations at Lateral side Lp (lateral proximal) and Ld (lateral distal); c Strain gauge location at Anterior side (A); d Strain gauges locations at Medial side Mp (medial proximal) and Md (medial distal); e Strain gauge location at Posterior side (P); $\mathbf{f}$ DIC image - stochastic pattern at Anterior femur side; g) DIC image - stochastic pattern at Posterior femur side 
anterior $(\mathrm{A})$ and posterior $(\mathrm{P})$ sides. The strain gauges positions were chosen in order to be located in the metaphyseal sleeve region (Fig. 2b, c, d and e). All strain gauges were connected to a data acquisition system PXI-1050 (National-Instruments, USA). Three load-cases (in extension) were applied experimentally. First, an axial load of $2030 \mathrm{~N}$ (3x bodyweight) was applied in the mid-shaft of the femur with the femoral-component in contact with the tibial tray (TestRessouces Axial-Torsion Test Machine, MN, USA), which due to the hold bar placed medially under the tibial tray support, a load repartition of $60 \%$ and $40 \%$ at the medial and lateral condyle respectively was guaranteed (Fig. 2a). The second load-case was a pure internal-external moment of $7 \mathrm{Nm}$ applied through the tibial tray to the femoral-component. The tibial tray support was fastened to the bench of the angle/moment actuator of the loading machine (Fig. 2). The third load-case was the combination of the two previous load-cases, where simultaneously the axial load of $2030 \mathrm{~N}$ and the internal-external moment of $7 \mathrm{Nm}$ were applied. These applied loads are representative of a normal physiological loading condition during walking at the stance phase before toe-off [24]. To correlate with finite-element models and evaluate the risk of strain-shielding at the metaphyseal cortex region, the maximum $(\varepsilon 1)$ and minimum $(\varepsilon 2)$ principal-strains within the plane of the gauge were calculated and averaged. The femoral-component total displacement (micromotion) relative to the anterior and posterior femoral cortex, was measured after 100 load cycles at a frequency of $1 \mathrm{~Hz}$, for each construct configuration, using the commercial DIC (Digital image correlation) system ARAMIS $5 \mathrm{M}$ (GOM Precise Industrial 3D Metrology, Germany). Images were acquired using Photron APX-RS high-speed cameras having a $2448 \times 2050$ pixel sensor along with $105 \mathrm{~mm}$ Fixed Focal Length Nikon lenses, pointed to the anterior and posterior femur region at $200 \mathrm{~mm}$. The field view was set to $50 \mathrm{~mm}$ (width) by $50 \mathrm{~mm}$ (height), with a depth field of $20 \mathrm{~mm}$. This volume is enough to frame the entire region of interest (ROI), first the anterior and then the posterior femur cortex. At the start of each test, a rigid calibration target was first moved in the location where the femur would be positioned for calibration of the DIC images. Images were taken every $0.1 \mathrm{~s}$ for the duration of the tests. ARAMIS v6.2.0-6 software was used to measure pixel displacement, and thus calculate the total relative displacements (micromotion) between the anterior cortex and the anterior femoral-component (a distance of $21 \mathrm{~mm}$ ) and between the posterior cortex and the posterior femoral-component (a distance of $35 \mathrm{~mm}$ ) (Fig. $2 \mathrm{f}$ and g).

\section{Finite-element analysis}

Finite-element (FE) models of the three implanted configurations were built from radiographs and CT-scans of the experimental models. Models meshes and non-linear analyses were performed with ABAQUS (Abaqus 2017, Simulia, Providence, USA). The cement-implant and implant-bone interfaces were modelled with a surface-tosurface contact algorithm using coefficients of friction of 0.25 and 0.3 [5] respectively. The bone-cement was considered rigidly bonded to the bone. The convergence rate of the maximum displacement of the FE models for more than 180,000 tetrahedral elements was less than $0.5 \%$, in all models. The materials were assumed to be homogeneous, isotropic and linearly elastic; the elastic modulus values adopted for the femoral component, sleeve and fluted stem, cement, cortical and cancellous bone were $210 \mathrm{GPa}, 110 \mathrm{GPa}, 16.7 \mathrm{GPa}$ and $0.155 \mathrm{GPa}$, respectively $[5,6]$. Poisson's ratio was considered to be 0.3 for all materials $[5,6]$. The three load-cases applied to the FE models replicates those used in the experimental setup. Principal bone strains acting on the gauge planes were selected corresponding to the experimental strain measurement sites. Regression analyses of the principal strains predicted by the FE models and measured strains were performed. The root-mean-square-error, expressed as a percentage (RMSE $\%$ ) of the peak values of the measured principal-strains, was used as an additional indicator of the overall absolute difference between numerical and experimental strains. The relative FE total displacement (micromotion) between the anterior and posterior femur cortex the femoralcomponent were compared with the experimental ones. To evaluate, cancellous bone failure risk in compression around the metaphyseal sleeve, comparative analyses of the minimal-principal-strains were conducted for each construct. Finally, the micro-movements between the metaphyseal-sleeve and the cancellous bone at the anterior, posterior, medial and lateral contact areas were evaluated.

\section{Statistical analysis}

An exploratory data analysis was made to check the normal distribution of all data. Paired t-tests were performed (SPSS, USA) to evaluate the statistical significance of the difference between mean principal strains and implant-cortex micromotions. Statistically, significant differences are considered for $p$-values lower than 0.05 . The sample size was based on the estimation of the standard deviation from previous identical studies [5-8] for a $\alpha=0.05$ and a power of 0.8 . The linear regression between all measured and finite-element principal cortex strains presented a correlation value $\left(R^{2}\right)$ of 0.98 and a slope of 1.01 (Fig. 3).

\section{Results}

\section{Experimental}

The means and standard deviations of cortex principalstrains at each strain gauge are presented in Fig. 4 for all 


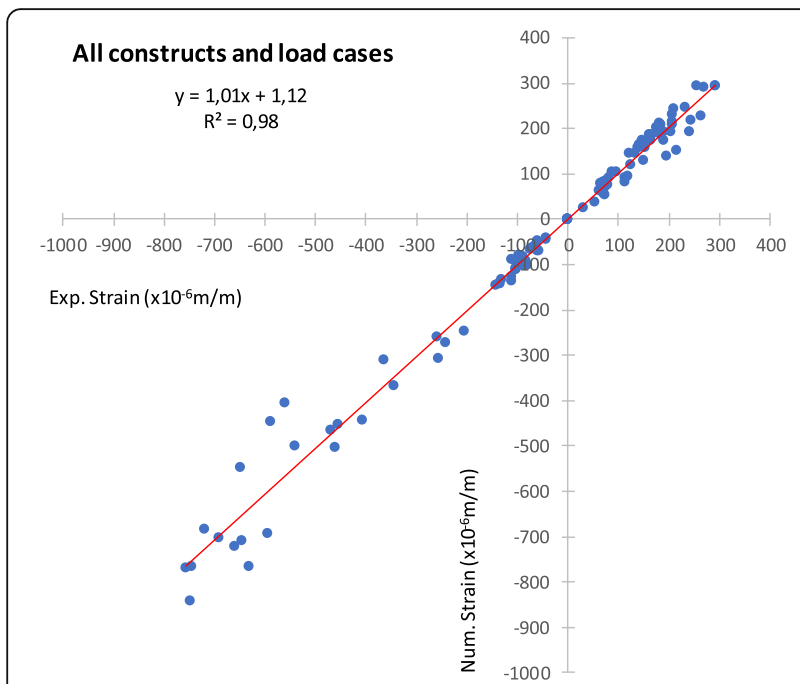

Fig. 3 Linear regression between experimental and numerical cortical strains (all strain gauges, all construct techniques and load cases)

load-cases. The average standard deviation of the principal-strains was less than $11 \%$ (Fig. 4). The Internal-External moment load case presents the lowest principal-strains of the three load-cases analysed with a nominal mean value below $150 \mu$ strain. The Axial and Axial + Internal-External moment load cases presented very similar cortex strain behaviour. On these load cases, the highest nominal minimum-principal-strains (compressive) were recorded at the medial $(\mathrm{Md}, \mathrm{Mp}$ ) and posterior $(\mathrm{P})$ strain gauges, while the highest maximumprincipal-strains (tensile) were measured at the lateral (Ld, Lp) and anterior (A) strain gauges. Excluding the Anterior (A) strain gauge, the magnitude of minimumprincipal-strains was greater than maximum-principalstrains, with nominal values of $750 \mu$ strain measured at the Posterior (P) and Medial-proximal (Mp) strain gauges. Significant principal cortex strain changes $(p<$ 0.05 ) between the three different techniques were observed mainly in the Axial and Axial + Internal-External moment load cases (Table 1). For these two load cases, only two strain gauges (33\%) presented significant principal strains changes between the techniques with femoral component (A) and stemless-sleeve (B). In contrast, a significant principal strain reduction in five straingauges $(83 \%)$ is present between the techniques with femoral component (A) and stemmed-sleeve (C).

The measured micromotions (DIC) between femoralcomponent and anterior and posterior cortex are presented in Table 2. No statistically significant micromotion differences were found between the techniques stemless-sleeve (B) vs. femoral component (A) and the stemmed-sleeve (C) vs. femoral component (A) for all load cases.

\section{Finite-element}

The overall absolute difference between finite-element and experimental cortex strains (RMSE \%) was $11 \%$. The difference between finite-element and experimental implant-cortex micromotion ranged between $-7 \mu \mathrm{m}$ and $+5 \mu \mathrm{m}$ (Table 2), which represents a mean difference of $15 \%$.

Figure 5 shows the patterns of the minimum-principalstrains in cancellous bone obtained in all FE analyses. The Internal-External moment load case has the lowest minimum-principal-strains in cancellous bone of all load cases, with nominal mean values below $-700 \mu$ strain at the sleeve region. Very similar cancellous bone strain behaviour is present in the Axial and Axial + IE moment load cases. The highest nominal minimum-principal-strains in cancellous bone were reached at the sleeve proximal region with peak values about $-3250 \mu$ strain, for both techniques stemless-sleeve (B) and stemmed-sleeve (C). These two techniques reduce about $50 \%$ the cancellous bone strain at the distal femur region (femoral-component) and an increase nearly four times at the proximal metaphyseal region around sleeve comparing to the model only with femoral component (A).

Micromotion on the cancellous bone-sleeve interface on the anterior, medial, lateral and posterior femur sides is presented in Table 3. The lowest micromotions, below $10 \mu \mathrm{m}$, were registered on the Internal-External moment load case, while the highest mean micromotions occurred in the Axial and Axial + IE moment load cases. For these two load cases, the lowest micromovements happened at the sleeve distal region, with values below the $16 \mu \mathrm{m}$, while at the proximal sleeve region were registered the peak values that ranged between the $28 \mu \mathrm{m}$ and $70 \mu \mathrm{m}$ for both techniques stemless-sleeve (B) and stemmed-sleeve $(C)$. No substantive micromotion differences were found between the different sleeve sides for all models. The diaphyseal-stem addition $(C)$ reduces the micromotions in all sleeve-bone interface sides relative to the stemless-sleeve technique (B), these reductions are more important at the proximal sleeve region with a mean value of $42 \%$, while at the sleeve distal region these reductions were $20 \%$.

\section{Discussion}

It was hypothesised that diaphyseal-stem addition increases the sleeve-femur interface stability and the strain-shielding effect on the metaphyseal femur in relation to the stemless condition. The obtained results to some extent contradict the study hypothesis. The use of a supplemental diaphyseal-stem potentiates the risk of cortex bone resorption compared with the stemlesssleeve condition; however, the stem is not essential to increase the initial sleeve-bone stability and has a minor effect on the cancellous bone strain behaviour. To the 


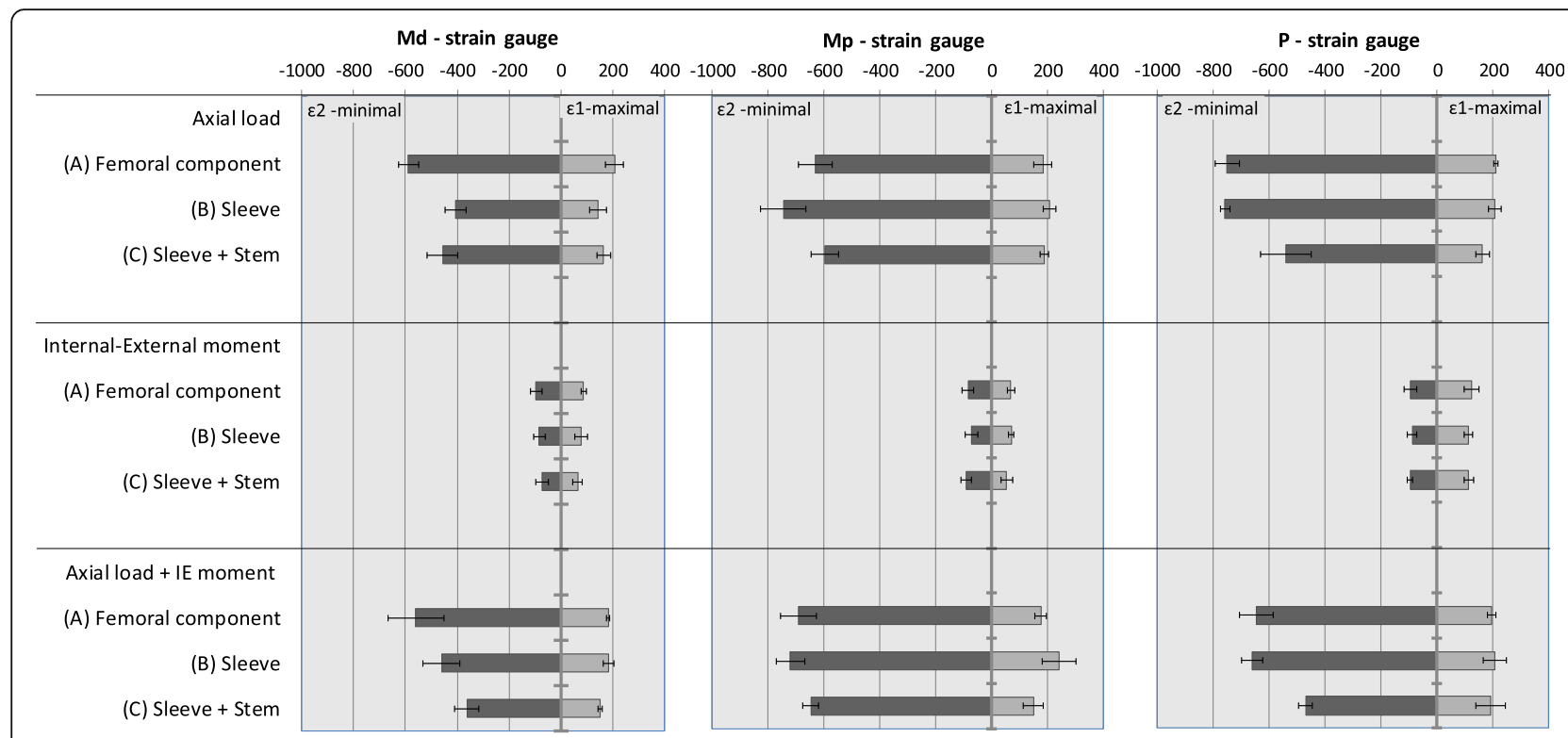

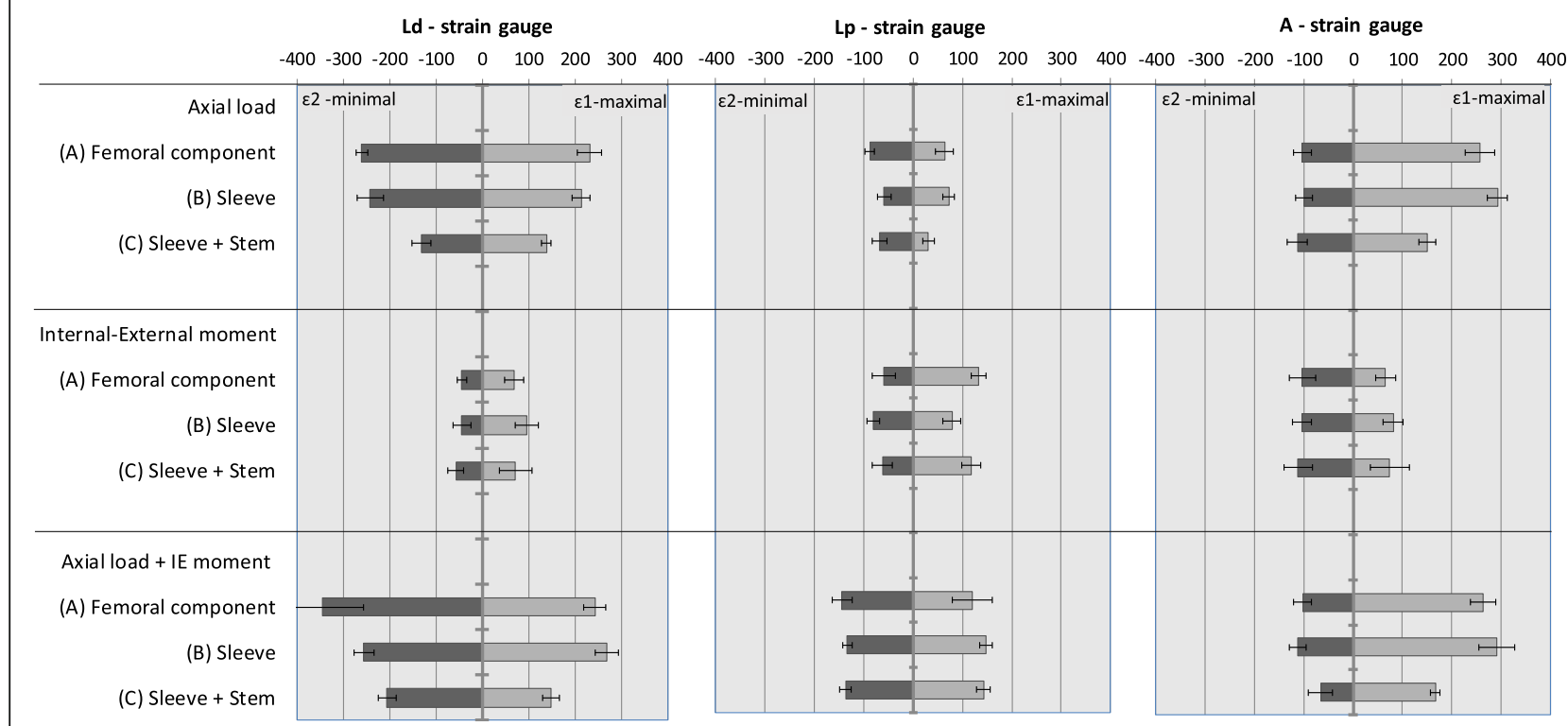

Fig. 4 Mean and standard deviation (error bars) of the measured principal strains ( $\varepsilon 1$ - maximal and $\varepsilon 2$ - minimal) at each strain gauge Md (medial distal), Mp (medial proximal), P (posterior), A (anterior), Ld (lateral distal) and Lp (lateral proximal) for each construct technique and load case

authors' knowledge, there are no other studies that had evaluated the contribution of the diaphyseal-stem for the initial sleeve-femur construct stability, as well as, the metaphyseal femur strain behaviour neither in-vitro nor using the FE method. The standard deviations of the measured cortex strains were within the range of those found in the literature which used the synthetic bone models $[6,23]$. The principal cortex strains behaviour for the Axial and Axial + Internal-External moment load cases were nearly identical, with nominal minimumprincipal-strains values, on average, 4 to 8 times greater than the Internal-External moment load case. These cortex strain differences, between load cases, are related with the great magnitude of the axial load component and their asymmetric distribution between the medial and lateral condyles on the tibial tray, which induce a frontal moment and thus high compressive and tensile strains at medial and lateral femur sides, respectively. The experimental cortex strain results demonstrate that metaphyseal femur cortex is apparently immune to the presence of the sleeve (B) or the sleeve + stem $(C)$ when only subjected to an Internal-External moment load. 
Table $1 P$-values obtained from T-tests to test differences between the means of the minimal ( $(2)$ and the maximal ( $\varepsilon 1)$ principal strains. For a level of significance a, statistically significant differences will be detected when $p$-value $<0.05$

\begin{tabular}{|c|c|c|c|c|c|c|}
\hline \multirow[t]{2}{*}{ Load case } & \multirow[t]{2}{*}{ Strain gauge } & & \multicolumn{2}{|c|}{$\begin{array}{l}\text { Femoral component (A) versus } \\
\text { Sleeve (B) }\end{array}$} & \multicolumn{2}{|c|}{$\begin{array}{l}\text { Femoral component }(A) \text { versus Sleeve }+ \\
\text { Stem (C) }\end{array}$} \\
\hline & & & $\varepsilon 2$ (minimal) & $\varepsilon 1$ (maximal) & $\varepsilon 2$ (minimal) & $\varepsilon 1$ (maximal) \\
\hline \multirow[t]{6}{*}{ Axial load } & Medial distal & Md & $0,002(P<0.01)$ & $0,02(P<0.05)$ & $0,004(P<0.01)$ & $0,005(P<0.01)$ \\
\hline & Medial proximal & Mp & NS & NS & NS & NS \\
\hline & Posterior & $P$ & NS & NS & $0,008(P<0.01)$ & $0,01(P<0.05)$ \\
\hline & Lateral distal & $\mathrm{Ld}$ & NS & NS & $0,001(P<0.01)$ & $0,001(P<0.01)$ \\
\hline & Lateral proximal & $L p$ & $0,01(P<0.05)$ & NS & $0,02(P<0.05)$ & $0,004(P<0.01)$ \\
\hline & Anterior & A & NS & NS & NS & $0,001(P<0.01)$ \\
\hline \multirow[t]{6}{*}{ Internal-External moment } & Medial distal & Md & NS & NS & NS & $0,01(P<0.05)$ \\
\hline & Medial proximal & $\mathrm{Mp}$ & NS & NS & NS & NS \\
\hline & Posterior & $P$ & NS & NS & NS & NS \\
\hline & Lateral distal & $\mathrm{Ld}$ & NS & NS & NS & NS \\
\hline & Lateral proximal & $L p$ & $0,02(P<0.05)$ & $0,001(P<0.01)$ & NS & NS \\
\hline & Anterior & A & NS & NS & NS & NS \\
\hline \multirow[t]{6}{*}{ Axial load + Internal-External moment } & Medial distal & Md & $0,01(P<0.05)$ & NS & $0,002(P<0.01)$ & $0,003(P<0.01)$ \\
\hline & Medial proximal & $\mathrm{Mp}$ & NS & $0,04(P<0,05)$ & $0,04(P<0.05)$ & NS \\
\hline & Posterior & $P$ & NS & NS & $0,002(P<0.01)$ & NS \\
\hline & Lateral distal & $\mathrm{Ld}$ & NS & NS & $0,02(P<0.05)$ & $0,002(P<0.01)$ \\
\hline & Lateral proximal & $L p$ & NS & NS & NS & NS \\
\hline & Anterior & A & NS & NS & $0,04(P<0.05)$ & $0,001(P<0.01)$ \\
\hline
\end{tabular}

However, when the axial load component is present the cortex strains are significantly reduced $(p<0.05)$ in $83 \%$ of strain gauges on stemmed-sleeve, which compares with $33 \%$ in stemless condition, relative to the femoral component alone (A). It is known that in situations where bone loads are reduced or eliminated, bone mass is reabsorbed [14]. However, the nominal metaphyseal cortex strain reduction was inferior to $50-200 \mu$ strain in most of the strain gauges, whereby seem to present a limited risk of change of the cortex remodelling process [10], i.e. not enough to reduce cortex bone density when compared with the femoral component alone (A).Overall, the stemmed-sleeve technique $(\mathrm{C})$ increased the femoral component stability relative to the anterior and posterior metaphyseal cortex when compared with the stemless-sleeve technique (B); however, no significant micromotions differences were found, when compared with the femoral component alone (A).

The FE models developed to assess the structural behaviour of cancellous bone presented a good correlation between numerical and experimental cortex strains in the range of previously published studies [7, 8], as well as implant-cortex stability presented reduced micromotion differences between numerical and experimental, which demonstrates the reliability of the FE models. The critical factor to the bone structure is the risk of failure of the supporting cancellous-bone in compression [4, 30]. The failure process of cancellous bone can be due to overload, and usually, it is a fatigue mode or failure described by Wolff's law; in situations where bone loads are reduced or eliminated, bone mass is reabsorbed [14]. When the axial load component is present, both techniques ( $\mathrm{B}$ and $\mathrm{C}$ ) presented identical peak minimum-principal cancellous bone strains values at the sleeve proximal region, increasing nearly four times relative to the model only with femoral component (A), while both techniques reduce cancellous bone strain at the distal femur region. The load transfer effect of the sleeve in both techniques increases the risk of proximal metaphyseal cancellous bone to suffer fatigue failure. It is reasonable to expect cancellous bone to suffer fatigue failure, when the number of cycles is greater than 1 million [30] if the induced strains are increased by 50 to $100 \%$ due to implantation [4], which is the present case. To reduce this risk, the limitation of the patient weight-bearing immediately after the revision with the sleeve can lead to the positive outcome of the procedure by reducing the overload effect at the proximal metaphyseal region. As previously mentioned, an important factor on the sleeve cancellous bone osseointegration is the interface micromotion amplitude $[26,29]$. The amplitude of micromotions should be $<150 \mu \mathrm{m}$ to achieve good osseointegration, higher amplitudes of the micromotions 


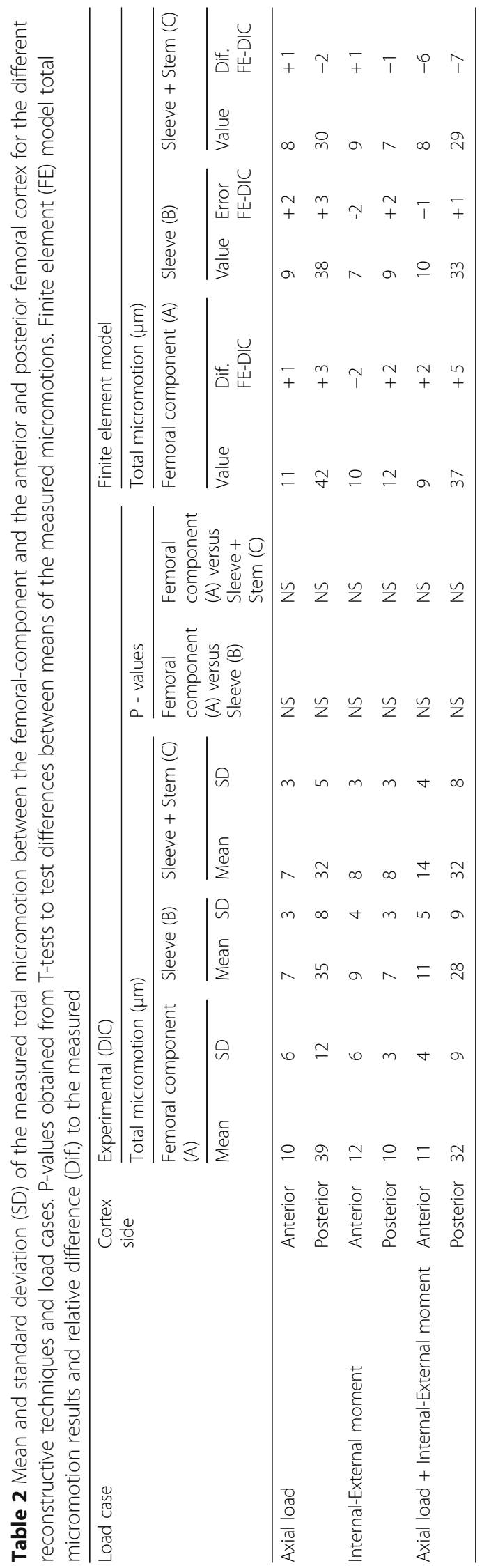




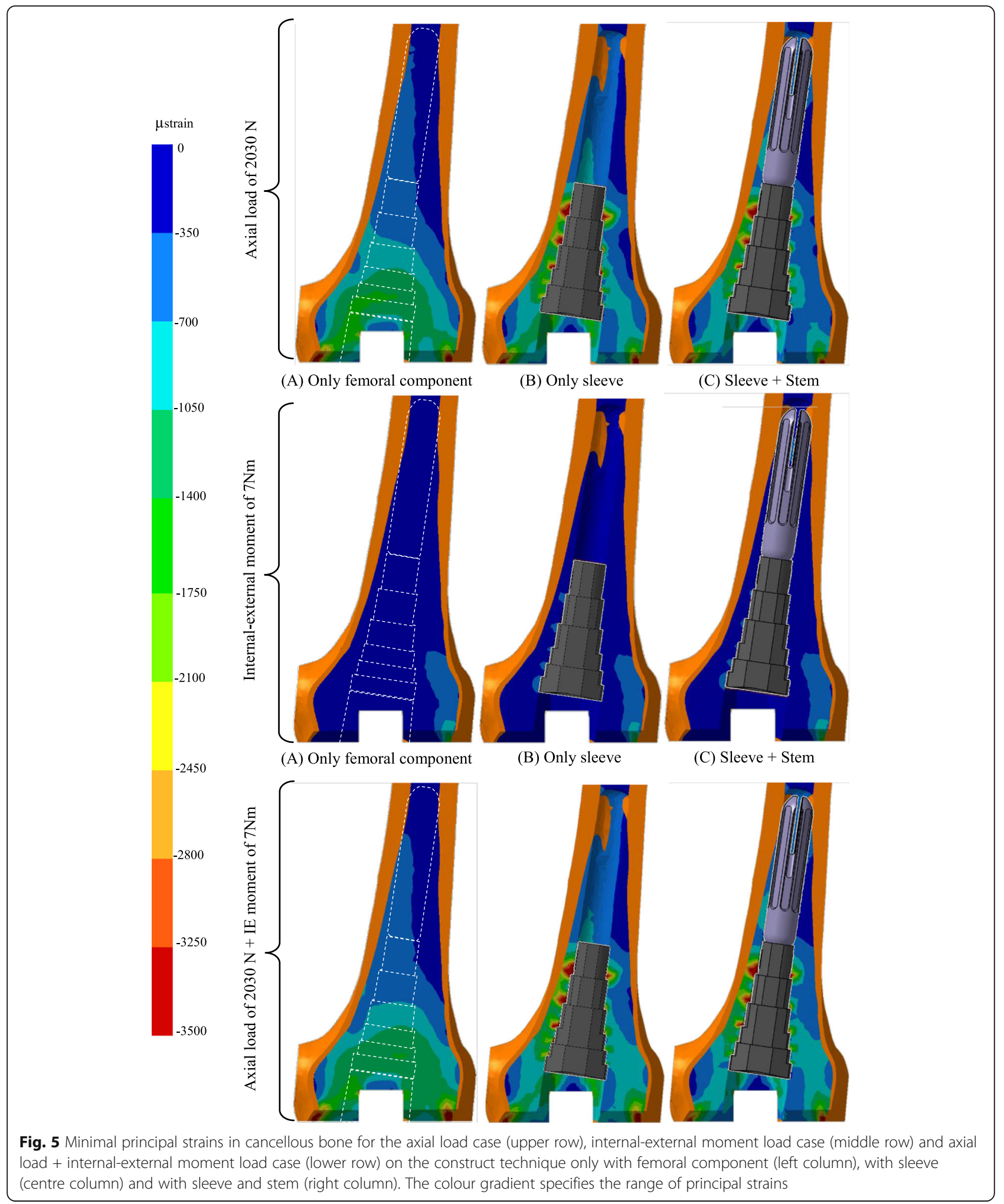

leads to the formation of fibrous tissue and future implant loosening [19]. The diaphyseal-stem addition (C) reduces the distal sleeve-bone interface micromotion; however, the maximum micromotion values on the stemless-sleeve technique (B) at the distal sleeve region (porous coated surfaces) were inferior to $33 \mu \mathrm{m}$. Given the obtained results, the average amplitude of micromotions for both techniques lies below the aforementioned critical limit of 
Table 3 Interface micromotions $(\mu \mathrm{m})$ between sleeve and cancellous-bone along medial, anterior, lateral and posterior sides

\begin{tabular}{|c|c|c|c|c|c|c|c|c|c|c|c|c|c|}
\hline \multirow{3}{*}{$\begin{array}{l}\text { Medial } \\
\text { Load } \\
\text { case } \\
(\mu \mathrm{m})\end{array}$} & & & & & & & \multicolumn{7}{|l|}{ Anterior } \\
\hline & \multicolumn{2}{|l|}{ Axial } & \multicolumn{2}{|c|}{ IE moment } & \multicolumn{2}{|c|}{$\begin{array}{l}\text { Axial + IE } \\
\text { moment }\end{array}$} & \multirow[t]{2}{*}{ Load case } & \multicolumn{2}{|l|}{ Axial } & \multicolumn{2}{|c|}{ IE moment } & \multicolumn{2}{|c|}{$\begin{array}{l}\text { Axial + IE } \\
\text { moment }\end{array}$} \\
\hline & $\begin{array}{l}\text { Only } \\
\text { Sleeve }\end{array}$ & $\begin{array}{l}\text { Sleeve + } \\
\text { stem }\end{array}$ & $\begin{array}{l}\text { Only } \\
\text { Sleeve }\end{array}$ & $\begin{array}{l}\text { Sleeve + } \\
\text { stem }\end{array}$ & $\begin{array}{l}\text { Only } \\
\text { Sleeve }\end{array}$ & $\begin{array}{l}\text { Sleeve + } \\
\text { stem }\end{array}$ & & $\begin{array}{l}\text { Only } \\
\text { Sleeve }\end{array}$ & $\begin{array}{l}\text { Sleeve + } \\
\text { stem }\end{array}$ & $\begin{array}{l}\text { Only } \\
\text { Sleeve }\end{array}$ & $\begin{array}{l}\text { Sleeve + } \\
\text { stem }\end{array}$ & $\begin{array}{l}\text { Only } \\
\text { Sleeve }\end{array}$ & $\begin{array}{l}\text { Sleeve + } \\
\text { stem }\end{array}$ \\
\hline \multirow{2}{*}{8} & 41 & 34 & 6 & 5 & 45 & 34 & \multirow[b]{2}{*}{ - } & 54 & 29 & 4 & 4 & 60 & 33 \\
\hline & 30 & 28 & 6 & 5 & 32 & 29 & & 35 & 24 & 4 & 3 & 39 & 25 \\
\hline \multirow{2}{*}{ - } & 23 & 21 & 5 & 5 & 25 & 23 & $\bullet$ & 20 & 18 & 3 & 3 & 22 & 19 \\
\hline & 20 & 19 & 5 & 4 & 23 & 20 & \multirow{2}{*}{ ? } & 18 & 15 & 3 & 3 & 21 & 17 \\
\hline - & 17 & 16 & 4 & 3 & 19 & 17 & & 16 & 13 & 3 & 2 & 18 & 14 \\
\hline 0 & 14 & 15 & 4 & 3 & 16 & 14 & : & 14 & 12 & 3 & 2 & 16 & 10 \\
\hline \multicolumn{7}{|l|}{ Lateral } & \multicolumn{7}{|l|}{ Posterior } \\
\hline \multirow{2}{*}{$\begin{array}{l}\text { Load } \\
\text { case } \\
(\mu \mathrm{m})\end{array}$} & \multicolumn{2}{|l|}{ Axial } & \multicolumn{2}{|c|}{ IE moment } & \multicolumn{2}{|c|}{$\begin{array}{l}\text { Axial + IE } \\
\text { moment }\end{array}$} & \multirow[t]{2}{*}{ Load case } & \multicolumn{2}{|l|}{ Axial } & \multicolumn{2}{|c|}{ IE moment } & \multicolumn{2}{|c|}{$\begin{array}{l}\text { Axial + IE } \\
\text { moment }\end{array}$} \\
\hline & $\begin{array}{l}\text { Only } \\
\text { Sleeve }\end{array}$ & $\begin{array}{l}\text { Sleeve + } \\
\text { stem }\end{array}$ & $\begin{array}{l}\text { Only } \\
\text { Sleeve }\end{array}$ & $\begin{array}{l}\text { Sleeve + } \\
\text { stem }\end{array}$ & $\begin{array}{l}\text { Only } \\
\text { Sleeve }\end{array}$ & $\begin{array}{l}\text { Sleeve + } \\
\text { stem }\end{array}$ & & $\begin{array}{l}\text { Only } \\
\text { Sleeve }\end{array}$ & $\begin{array}{l}\text { Sleeve + } \\
\text { stem }\end{array}$ & $\begin{array}{l}\text { Only } \\
\text { Sleeve }\end{array}$ & $\begin{array}{l}\text { Sleeve + } \\
\text { stem }\end{array}$ & $\begin{array}{l}\text { Only } \\
\text { Sleeve }\end{array}$ & $\begin{array}{l}\text { Sleeve + } \\
\text { stem }\end{array}$ \\
\hline \multirow{2}{*}{8} & 64 & 38 & 5 & 5 & 70 & 40 & \multirow[b]{2}{*}{$\bullet$} & 48 & 25 & 10 & 8 & 52 & 28 \\
\hline & 40 & 32 & 5 & 4 & 43 & 34 & & 35 & 22 & 8 & 7 & 37 & 25 \\
\hline \multirow{2}{*}{ - } & 30 & 25 & 4 & 4 & 33 & 26 & $\bullet$ & 27 & 19 & 7 & 7 & 29 & 20 \\
\hline & 20 & 18 & 3 & 3 & 22 & 19 & \multirow{2}{*}{ - } & 22 & 17 & 5 & 4 & 23 & 18 \\
\hline & 16 & 15 & 3 & 2 & 17 & 15 & & 18 & 14 & 4 & 4 & 19 & 14 \\
\hline - & 12 & 10 & 2 & 2 & 12 & 9 & - & 12 & 11 & 3 & 3 & 14 & 9 \\
\hline$\bullet$ & & & & & & & - & & & & & & \\
\hline
\end{tabular}

$150 \mu \mathrm{m}$. Therefore, it can be concluded that the general mechanical performance of both techniques, stemless and stemmed, are suitable for bone ingrowth.

The present study has limitations. The first one is related to the use of synthetic femur and to simplifications in the experiments to represent the functioning knee after revision with a metaphyseal femoral sleeve. However, the flexural and torsional rigidity of synthetic femur is within the range of values verified for healthy adult bones; also the failure modes of the synthetic models are close to published data for human bones [11]. Another limitation is the simplified loads applied, although they are representative of the major loads acting upon the implant and femur structure. In addition, this study does not account for the associated thinning, quality of the cortices, loss of density in the adjacent cancellous bone and different metaphyseal bone defect geometries. In an in vivo situation these parameters will affect the load share and the implant stability; even so, it seems reasonable to expect that these conditions will affect in the same way the different techniques. Even though, the goal of this study was to gain understanding on how the two techniques applied in identical femur conditions can be associated with a life expectancy of the revision procedure; this insight will lead to an improved surgical decision process, which will be based on independent scientific understanding and advanced prediction tools.

\section{Conclusions}

The use of a supplemental diaphyseal-stem may increase the risk of cortex bone resorption compared with the stemless-sleeve condition; moreover, the stem is not essential to enhance the initial sleeve-bone stability. Both techniques are suitable for sleeve-bone ingrowth, and the diaphyseal-stem also, has minor effect on the cancellous bone strain behaviour; the limit on patient weightbearing after the revision procedure can contributes to the reduction of the overload effect at the proximal sleeve region. Based on a purely structural point view, it appears that the use of a diaphyseal-femoral-stem with the metaphyseal sleeve is not mandatory in the revision. These findings do not fully support the study original hypothesis.

\section{Acknowledgements}

The authors acknowledge the financial support through project POCl-010145-FEDER-028424-PTDC/EME-SIS/28424/2017, which was funded by the Operational Program for Competiveness and Internationalization (COMPETE 2020) in its component FEDER and by Science and Technology Foundation (FCT) through the OE budget. 


\section{Authors' contributions}

FF conceived of the study and participated in its design, AS participated in the statistical analysis and AC participated in the sequence alignment and drafted the manuscript. The author FF, AS and AC read and approved the final manuscript.

\section{Competing interests}

The authors declare that they have no conflict of interest.

\section{Author details}

'Orthopaedic Surgery Department, Coimbra University Hospitals, Coimbra, Portugal. ${ }^{2}$ Mechanical Engineering Department, University of Aveiro, 3810-193 Aveiro, Portugal.

Received: 11 February 2020 Accepted: 9 April 2020

Published online: 26 April 2020

\section{References}

1. Agarwal S, Azam A, Morgan-Jones R (2013) Metal metaphyseal sleeves in revision total knee replacement. Bone Joint J 95-B:1640-1644

2. Alexander GE, Bernasek TL, Crank RL, Haidukewych GJ (2013) Cementless metaphyseal sleeves used for large tibial defects in revision total knee arthroplasty. J Arthroplast 28:604-607

3. Bugler KE, Maheshwari R, Ahmed I, Brenkel IJ, Walmsley PJ (2015) Metaphyseal sleeves for revision Total knee Arthroplasty: good short-term outcomes. J Arthroplast 30:1990-1994

4. Choi K, Goldstein SA (1992) A comparison of the fatigue behavior of human trabecular and cortical bone tissue. J Biomech 25:1371-1381

5. Completo A, Fonseca F, Ramos A, Simões JC (2017) Comparative assessment of different reconstructive techniques of distal femur in revision total knee arthroplasty. Knee Surg Sports Traumatol Arthrosc 25:2559-2566

6. Completo A, Fonseca F, Simões JA, Ramos A, Relvas C (2012) A new press-fit stem concept to reduce the risk of end-of-stem pain at revision TKA: a preclinical study. Knee. 19:537-542

7. Completo A, Fonseca F, Relvas C, Ramos A, Simões JA (2012) Improved stability with intramedullary stem after anterior femoral notching in total knee arthroplasty. Knee Surg Sports Traumatol Arthrosc 20:487-494

8. Completo A, Pereira J, Fonseca F, Ramos A, Relvas C, Simões J (2011) Biomechanical analysis of total elbow replacement with unlinked iBP prosthesis: an in vitro and finite element analysis. Clin Biomech 26:990-997

9. Fedorka CJ, Chen AF, Pagnotto MR, Crossett LS, Klatt BA (2018) Revision total knee arthroplasty with porous-coated metaphyseal sleeves provides radiographic ingrowth and stable fixation. Knee Surg Sports Traumatol Arthrosc 26:1500-1505

10. Frost HM (2003) Bone's Mechanostat: a 2003 update. Anat Rec A Discov Mol Cell Evol Biol 275:1081-1101

11. Gardner MP, Chong AC, Pollock AG, Wooley PH (2010) Mechanical evaluation of large-size fourth-generation composite femur and tibia models. Ann Biomed Eng 38:613-620

12. Graichen H, Scior W, Strauch M (2015) Direct, Cementless, Metaphyseal Fixation in Knee Revision Arthroplasty With Sleeves-Short-Term Results. J Arthroplasty 30:2256-2259

13. Gøttsche D, Lind T, Christiansen T, Schrøder HM (2016) Cementless metaphyseal sleeves without stem in revision total knee arthroplasty. Arch Orthop Trauma Surg 136:1761-1766

14. Gross TS, Rubin CT (1995) Uniformity of resorptive bone loss induced by disuse. J Orthop Res 13:708-714

15. Haidukewych GJ, Hanssen A, Jones RD (2011) Metaphyseal fixation in revision total knee arthroplasty: indications and techniques. J Am Acad Orthop Surg. 19:311-318

16. Heiner A (2008) Structural properties of fourth-generation composite femurs and tibias. J Biomech 41:3282-3284

17. Ihekweazu UN, Weitzler L, Wright TM, Padgett DE (2019) Distribution of Bone Ongrowth in Metaphyseal Sleeves for Revision Total Knee Arthroplasty: A Retrieval Analysis. J Arthroplasty 34:760-765

18. Inacio MCS, Paxton EW, Graves SE, Namba RS, Nemes S (2017) Projected increase in total knee arthroplasty in the United States - an alternative projection model. Osteoarthr Cartil 25:1797-1803

19. Jasty M, Bragdon C, Burke D, O'Connor D, Lowenstein J, Harris WH (1997) In vivo skeletal responses to porous-surfaced implants subjected to small induced motions. J Bone Joint Surg Am 79:707-714
20. Kurtz S, Ong K, Lau E, Mowat F, Halpern M (2007) Projections of primary and revision hip and knee arthroplasty in the United States from 2005 to 2030. J Bone Joint Surg Am 89:780-785

21. Mancuso F, Beltrame A, Colombo E, Miani E, Bassini F (2017) Management of metaphyseal bone loss in revision knee arthroplasty. Acta Biomed 88:98111

22. Martin-Hernandez C, Floria-Arnal LJ, Muniesa-Herrero MP, EspallargasDoñate T, Blanco-Llorca JA, Guillen-Soriano M, Ranera-Garcia M (2017) Midterm results for metaphyseal sleeves in revision knee surgery. Knee Surg Sports Traumatol Arthrosc 25:3779-3785

23. Meireles S, Completo A, Simões J, Flores P (2010) Strain shielding in distal femur after patellofemoral arthroplasty under different activity conditions. J Biomech 43:477-484

24. Morrison JB (1970) The mechanics of the knee joint in relation to normal walking. J Biomech 3:51-61

25. Morgan-Jones R, Oussedik SI, Graichen H, Haddad FS (2015) Zonal fixation in revision total knee arthroplasty. Bone Joint J. 97-B:147-149

26. Peters PC, Engh GA, Dwyer KA, Vinh TN (1992) Osteolysis after total knee arthroplasty without cement. J Bone Joint Surg Am 74:864-876

27. Sheth NP, Bonadio MB, Demange MK (2017) Bone loss in revision Total knee Arthroplasty: evaluation and management. J Am Acad Orthop Surg 25: 348-357

28. Stefani G, Mattiuzzo V, Prestini G (2017) RevisionTotal knee Arthroplasty with Metaphyseal sleeves without stem: short-term results. Joints. 5:207-211

29. Sugiyama $H$, Whiteside LA, Kaiser AD (1989) Examination of rotational fixation of the femoral component in total hip arthroplasty. A mechanical study of micromovement and acoustic emission. Clin Orthopaedics 249: 122-128

30. Taylor M, Tanner KE (1997) Fatigue failure of cancellous bone: a possible cause of implant migration and loosening. J-Bone-Joint-Surg Br 79:181-182

31. Thorsell M, Hedström M, Wick MC, Weiss RJ (2018) Good clinical and radiographic outcome of cementless metal metaphyseal sleeves in total knee arthroplasty. Acta Orthop 89:84-88

32. Watters TS, Martin JR, Levy DL, Yang CC, Kim RH, Dennis DA (2017) Porouscoated Metaphyseal sleeves for severe femoral and Tibial bone loss in revision TKA. J Arthroplast 32:3468-3473

33. Zanirato A, Cavagnaro L, Basso M, Divano S, Felli L, Formica M (2018) Metaphyseal sleeves in total knee arthroplasty revision: complications, clinical and radiological results. A systematic review of the literature. Arch Orthop Trauma Surg 138:993-1001

\section{Publisher's Note}

Springer Nature remains neutral with regard to jurisdictional claims in published maps and institutional affiliations.

\section{Submit your manuscript to a SpringerOpen ${ }^{\circ}$ journal and benefit from:}

- Convenient online submission

- Rigorous peer review

- Open access: articles freely available online

- High visibility within the field

- Retaining the copyright to your article

Submit your next manuscript at $>$ springeropen.com 